\title{
Young children in different linguistic environments: A multimodal neuroimaging study of the inferior frontal gyrus
}

Camilia Thieba ${ }^{1,2}$ camilia.thieba@ucalgary.ca

Xiangyu Long 1,2,3 xiangyu.long@ucalgary.ca

Deborah Dewey ${ }^{2,4}$ dmdewey@ucalgary.ca

Catherine Lebel 1,2,3 clebel@ucalgary.ca

Department of Radiology ${ }^{1}$

Alberta Children's Hospital Research Institute ${ }^{2}$

Hotchkiss Brain Institute ${ }^{3}$

Departments of Pediatrics and Community Health Sciences ${ }^{4}$

University of Calgary, Calgary, Alberta, Canada

2500 University Drive NW

Calgary, AB. T2N 1N4

Corresponding Author:

Catherine Lebel

Alberta Children's Hospital

2888 Shaganappi Trail NW

Calgary, Alberta, Canada

T3B 6A8

Word count: 3835 ; abstract: 200

Figures: 3

Tables: 2

Total pages: 31 


\begin{abstract}
Magnetic resonance imaging (MRI) studies show that bilingual adults display structural and functional brain alterations, especially in the inferior frontal gyrus (IFG), dependent on when they learned their second language. However, it is unclear whether these differences are due to early exposure to another language, or to lifelong adaptation. We studied 22 children aged 3-5 years growing up in a multilingual environment and 22 ageand sex-matched controls exposed to an English-only environment. Resting-state functional MRI and T1-weighted MRI were used to assess functional connectivity and structure of the IFG. Children in a multilingual environment had higher functional connectivity between the left IFG and dorsal language and attention areas, and between the right IFG and visual cortex, compared to children from a monolingual environment. Children in a multilingual environment also displayed decreased functional connectivity to temporal, anterior cingulate, and prefrontal areas. No significant group differences in IFG structure were observed. Our results suggest a more integrated functional language network, which is more segregated from other networks, in children who grow up in a multilingual environment. These findings suggest that functional alterations to the IFG due to second language learning occur early, while structural changes may not be apparent until later.
\end{abstract}

Keywords: Bilingualism; fMRI; language; inferior frontal gyrus; brain structure; functional connectivity 


\section{Introduction}

The brain grows and changes in response to experiences and stimuli throughout an individual's life. Learning language(s) is a fundamental skill, and many people learn more than one language at some point in their lives. Over half (54\%) of Europeans are able to hold conversations in more than one language (European Commission, DirectorateGeneral for Education and Culture, 2012) and 16-18\% of North Americans speak more than one language (Lepage and Corbeil, 2013; Ryan, 2013). Bilingualism and multilingualism are associated with improvements in some cognitive abilities (reviewed in Barac et al., Bialystok et al., 2014 and for meta-analysis see Adesope et al., 2010). Infants 6-12 months of age in bilingual homes exhibit better basic processing of nonlinguistic visual information and flexibility of attention than infants in monolingual homes (Kovács and Mehler, 2009a, 2009b; Singh et al., 2015). Bilingual adults and children as young as three years also perform better than their monolingual counterparts on language tasks requiring controlled attention and inhibition (Bialystok et al., 2005; Bialystok et al., 2004; Bialystok \& Martin, 2004; Bialystok \& Senman, 2004; Bialystok \& Shapero, 2005; Costa et al., 2009; Costa, Hernández, \& Sebastián-Gallés, 2008; Thomas-Sunesson et al, 2016), which could convey an advantage in solving problems that contain conflicting or misleading cues. The advantage in inhibitory control seen in bilingual children appears to be maintained into adulthood (Bialystok et al., 2004; Costa et al., 2009, 2008; Gollan et al, 2002; Sadat et al., 2012; Thomas-Sunesson et al., 2016).

Studies investigating the neural correlates of bilingualism and multilingualism have largely focused on adults, and consistently highlight the role of the inferior frontal gyrus (IFG). Specifically, the left IFG, which incorporates Broca's area, has been associated 
with language skills including phonological processing and language production (Pugh et al., 1996). During semantic and phonological language processing in first and second languages, bilingual adults activate the left IFG (Klein et al., 1995), and the IFG shows increased activity in bilingual compared to monolingual adults during naming and semantic processing tasks (Parker Jones et al., 2012; Kovelman et al., 2008a; Kovelman et al., 2008b). The IFG is also structurally different in bilingual compared to monolingual adults, and shows different patterns of resting state functional connectivity (Berken et al., 2017; Klein et al., 2014; Yamamoto and Sakai, 2016). Furthermore, second language training in adults induces changes to brain activity and cortical thickness in the IFG (Mårtensson et al., 2012; Mei et al., 2014).

Traditionally, individuals who speak at least two languages are categorized as either early or late bilinguals. Early, or simultaneous bilinguals acquire their second language alongside their native language, prior to age five years; late, or sequential bilinguals acquire their second language after five years of age. Early bilinguals often have better proficiency and a native-like accent compared to late bilinguals (Hakuta et al., 2003; Johnson, 1992; Johnson and Newport, 1989; Oyama, 1976; Patkowski, 1980; Stevens, 1999; Wartenburger et al., 2003). They also display different neural organisation than late bilinguals, in terms of both brain structure and function (Berken et al., 2016; Hernandez et al., 2015; Klein et al., 2014). Specifically, early or simultaneous bilingual adults exhibit greater bi-hemispheric functional connectivity between the left and right IFG, and between the IFG and areas involved in language control, compared to late or sequential bilinguals (Berken et al., 2016). The age at which a second language is learned is positively correlated with left IFG thickness and negatively correlated with right IFG 
thickness (Klein et al., 2014); age of acquisition is also related to functional connectivity between the left and the right IFG and the right inferior parietal lobe (Berken et al., 2016), and is associated with brain activation during grammatical judgement

(Wartenburger et al., 2003). Previous neuroimaging research on bilingualism has focused on older children or adults, so the associations between exposure to multiple languages and brain structure and function in early childhood remain unclear. Given that the IFG supports language functions including reading (Martin et al., 2015) and has been identified as a neural locus of language and executive control in the bilingual brain (Coderre et al., 2016), we aimed to gain a deeper understanding of its function and structure in young children, as they are exposed to another language. We compared structure and function of the IFG in children raised in a monolingual environment to those raised in a multilingual environment. Given previous findings showing relationships between age of second language acquisition and both cortical thickness (Klein et al., 2014) and functional connectivity (Berken et al., 2016) in the IFG, we hypothesized that children growing up in a multilingual environment would have thicker cortex and stronger functional connectivity in the left IFG compared to their monolingual peers.

\section{Materials and Methods}

\subsection{Participants}

Forty-four typically developing children were recruited from an ongoing, prospective study that recruited mothers during pregnancy (Kaplan et al., 2014). These children were all right-handed with no history of brain disease or trauma, and no diagnosed psychiatric, 
behavioral, or developmental disorders. Twenty-two children growing up in a multilingual environment aged 3.5 to 5.8 years $(4.8 \pm 0.6,14$ male / 8 female) were matched by sex and age with 22 children aged 3.8 to 5.9 years $(4.8 \pm 0.6,14$ male / 8 female) who were growing up in a monolingual (English) environment. Table 1 provides information on the sociodemographic characteristics of the children. Parents completed the Language Use Inventory (O'Neill, 2007), which asks about the child's exposure to languages. All children spoke and understood English. Parents were asked whether their children were regularly exposed to another language, when that exposure began, the method of exposure (e.g., daycare, parent), and to estimate the percentage of time their child was exposed to language(s) other than English at the time of the MRI scan.

\subsection{Assessments}

The English language abilities of the children were assessed using the NEPSY-II Phonological Processing and Speeded Naming subtests (Korkman et al., 2007). Throughout the preschool years, phonological awareness and naming speed have been found to be good predictors of later reading abilities (Logan et al., 2011). Maternal education (number of years of postsecondary education) and household income were acquired and used as proxies for socioeconomic status.

\subsection{Image acquisition}

All participants were imaged at the Alberta Children's Hospital on a GE 3T MR750w (General Electric, Waukesha, Wisconsin) using a 32-channel head coil, while awake and watching a movie. T1-weighted images obtained using a 3D spoiled gradient echo sequence with $0.9 \times 0.9 \times 0.9 \mathrm{~mm}^{3}$ spatial resolution, $\mathrm{TR}=8.2 \mathrm{~ms}, \mathrm{TE}=3.8 \mathrm{~ms}, \mathrm{TI}=540$ ms, matrix size $=256 \times 256 \times 214$, flip angle $=12^{\circ}$, lasting approximately 4 minutes. 
Resting-state fMRI was acquired using a gradient echo EPI sequence with the following parameters: $\mathrm{TR}=2000 \mathrm{~ms} ; \mathrm{TE}=30 \mathrm{~ms}$; matrix size $=64 \times 64,250$ volumes; flip angle $=60^{\circ}$; voxel size $=3.6 \times 3.6 \times 3.6 \mathrm{~mm}$. Thirty-six slices were acquired for a total of 250 volumes in 8 min $20 \mathrm{~s}$.

\subsection{Image analysis}

2.4.1 Structural imaging. T1-weighted images were processed using FreeSurfer 5.3 (Fischl, 2012), and normalized to a pediatric template (4.5-8.5 years) in MNI space (Fonov et al., 2011;Fonov et al., 2009) with linear registration. Each parcellation was visually inspected and manually corrected as necessary. Using the Automated Anatomic Labeling (AAL) atlas (Tzourio-Mazoyer et al., 2002), 3 regions of interest (ROIs) within the IFG were extracted for each child for each hemisphere: the pars triangularis (BA 45), pars opercularis (BA 44) and pars orbitalis (BA 47). For each ROI for each participant, mean cortical volume $\left(\mathrm{mm}^{3}\right)$, surface area $\left(\mathrm{mm}^{2}\right)$ and thickness $(\mathrm{mm})$ were calculated. Group differences were tested using independent sample t-tests in SPSS version 24. Significance was set to $\mathrm{p}<0.05$, with correction for 18 comparisons using the false discovery rate (FDR) correction (Genovese et al., 2002).

As an exploratory analysis of the rest of the brain, we also examined cortical volume, surface area, and thickness in all 68 anatomical regions (34 per hemisphere) defined by FreeSurfer's cortical parcellation (Desikan et al., 2006)(“aparc"). Independent sample ttests were used to test whether these measures differed significantly between groups.

2.4.2 Functional imaging. Functional image processing was performed in AFNI 16.2.12 (Cox, 1996) and FSL (Jenkinson et al., 2012). The first 10 volumes of the resting state data were excluded to allow for MR signal stabilization. Standard pre-processing 
steps were used: slice-timing, motion correction, white matter, cerebral spinal fluid and global signal regression, and temporal filtering $(0.009-0.1 \mathrm{~Hz})$. Relative high motion volumes ( $>0.3 \mathrm{~mm}$ framewise displacement, $>0.3 \%$ change in signal intensity) were censored using FSL Motion Outliers and regression analysis. All children had at least five minutes of low motion $(<0.3 \mathrm{~mm})$ data. Functional images were spatially normalized to a high-resolution pediatric template (4.5-8.5 years) in MNI space (Fonov et al., 2011; Fonov et al., 2009) with linear registration, and spatially smoothed (FWHM=4mm).

Seed-based functional connectivity analysis was performed using the 6 ROIs from the T1-weighted image analysis. First-level correlation maps were produced by extracting the average residual blood oxygen-level-dependent (BOLD) time course from the seed regions and computing Pearson's correlation coefficients between that time course and the time course of all other voxels. Correlation coefficients were converted to normally distributed z-scores using the Fisher's z transformation. Connectivity maps were compared between the two groups for each ROI using the general linear model, controlling for each child's age and sex. Multiple comparison cluster-level correction was done using $3 \mathrm{dClustSim}$ at $\mathrm{p}<0.05$ (voxel-level $\mathrm{p}<0.05$, cluster size $>2403 \mathrm{~mm}^{3}$ ).

2.4.3 Functional connectivity and language abilities. To examine whether there were group differences in the relationships between functional connectivity and language abilities, we extracted significant clusters from the original functional connectivity analysis (2.4.2), and used a multiple linear regression that included Phonological Processing, group, and the Phonological Processing-by-group interaction term. The same analysis was then repeated for Speeded Naming scaled scores. 
2.4.4 Relationships with exposure to language. As a follow-up analysis, we examine whether IFG functional connectivity to brain regions that had significant group differences was related to the amount of time exposed to additional languages. For the functional connectivity analysis, average beta weights were extracted within clusters showing significant group differences in functional connectivity, and a correlation was conducted between beta weights and percent of time exposed to other languages, controlling for age and sex. This analysis was performed only for children growing up in a multilingual environment.

\section{Results}

\subsection{Demographics and language scores}

The twenty-two children identified as growing up in a multilingual environment were regularly exposed to one or more of the following languages: French, Spanish, Filipino, Chinese, Dutch, Cantonese, Latvian, Mandarin, Bengali, Korean, and German. Children were regularly exposed to multiple languages through family members or nannies $(n=10)$, childcare or school settings $(n=8)$, or both $(n=4)$. Age of first exposure to the other language(s) ranged from 0-3 years, with most children $(\mathrm{n}=14)$ exposed from birth. At the time of the scan, the percent of time exposed other languages ranged from 10-50\% $($ mean $=20 \%)$.

Children growing up in a monolingual environment did not significantly differ from those growing in a multilingual environment on NEPSY-II Phonological Processing and Speeded Naming scores, household income, or maternal years of post-secondary education (see Table 1). 


\subsection{IFG and whole brain structure}

The two groups of children had no significant differences in IFG structure after FDRcorrection. For uncorrected values, children growing up in a multilingual environment had a thicker cortex (mean difference $=0.21 \mathrm{~mm} ; \mathrm{p}=0.039)$ in the left pars opercularis (BA 44) compared to children exposed to a monolingual environment. There were no significant group differences (corrected or uncorrected) in cortical volume or surface area.

In the exploratory whole-brain analysis, no group differences were significant following FDR correction for multiple comparisons. Uncorrected values revealed that children in the multilingual group had thicker cortex in the right caudal middle frontal (mean difference $=0.14 \mathrm{~mm} ; \mathrm{p}=0.025$ ); larger volume in the left caudal anterior cingulate (mean difference $=0.00014 \mathrm{~mm}^{3} ; \mathrm{p}=0.016$ ), the left caudal middle frontal (mean difference $=0.00025 \mathrm{~mm}^{3} ; \mathrm{p}=0.005$ ), and the right middle temporal gyrus (mean difference $\left.=0.00034 \mathrm{~mm}^{3} ; \mathrm{p}=0.044\right)$ compared to children in the monolingual group. No differences in cortical surface area were detected.

\subsection{IFG functional connectivity}

Children in a multilingual environment exhibited stronger functional connectivity between the left pars triangularis seed region and a large cluster spanning the bilateral superior parietal lobule (SPL), compared to children in the monolingual group (Fig. 1a; Table 2). Children in a monolingual environment displayed stronger connectivity between the left pars triangularis and the inferior and middle temporal gyri. A similar 
result was found for the left pars orbitalis seed region, where children in the multilingual group had stronger functional connectivity to the bilateral superior parietal lobule (SPL) and monolingual children had stronger functional connectivity to the middle frontal gyrus (Fig. 1b; Table 2). No significant differences were detected in functional connectivity from the left pars opercularis.

The multilingual group exhibited reduced functional connectivity from the right pars triangularis and pars opercularis seed regions to the anterior cingulate cortex, compared to monolinguals (Fig 2 a and b; Table 2). The multilingual group also showed reduced functional connectivity from the right pars opercularis seed region to the left inferior parietal lobule (Fig. 2b; Table 2). We also found that children in a multilingual environment had decreased functional connectivity from the right orbitalis to the left middle frontal gyrus (Fig. 2c; Table 2).

\subsection{Functional connectivity and language abilities}

There was a significant interaction between group and NEPSY-II Phonological Processing scaled scores for functional connectivity from the right pars orbitalis to the left middle frontal gyrus $(p=0.009, t=-2.79)$. In the monolingual group, performance was positively associated with the strength of the connectivity $(r=0.39)$ while in the multilingual group, performance was negatively associated with connectivity $(r=-0.47)$ (Figure 3A). Similarly, connectivity from the left pars orbitalis to the left middle frontal gyrus showed an interaction for Speeded Naming scaled scores $(\mathrm{p}=0.05, \mathrm{t}=-2.03)$, where the monolingual group had a positive relationship $(\mathrm{r}=0.30)$ and the multilingual group had a negative relationship $(\mathrm{r}=-0.37)$ between language scores and connectivity (Figure 3B). 


\subsection{Functional connectivity, structure and exposure to language}

There were no significant correlations between functional connectivity in the regions that showed group differences (see Table 2) and the percentage of time exposed to languages other than English in the multilingual group ( $\mathrm{p}<0.05$, uncorrected).

\section{Discussion}

In this study of young children in mono- and multilingual environments, differences of functional connectivity, but not structure, were detected in the IFG. Children growing up in a multilingual environment displayed higher functional connectivity between the IFG and language processing areas along the dorsal language and attention networks, and reduced connectivity to certain areas of the default mode and ventral attention networks. Together with previous findings in adults and older children, these findings suggests that functional alterations in the IFG are evident in young children learning multiple languages, whereas structural differences may emerge later.

Functional connectivity within the reading and language network is positively correlated with reading ability in both native and second languages in adults and children (Koyama et al., 2011; Zhang et al., 2014). Stronger functional connectivity within the language network has been shown to predict an adult's capacity to learn a second language (Chai et al., 2016), and adults who are early bilinguals exhibit stronger functional connectivity from the IFG to brain regions involved in language control than late bilinguals (Berken et al., 2016). Furthermore, functional connectivity of the right IFG is related to the age of acquisition of a second language (Berken et al., 2016). Our results provide similar evidence in younger children, demonstrating that preschoolers exposed to 
multiple languages have stronger functional connectivity from the IFG to other brain language regions, and suggesting that functional brain changes occur during the process of learning a second language.

Children growing up in a multilingual environment had increased functional connectivity between the IFG and the superior parietal cortex, part of the dorsal attention network. Given that the dorsal attention network is related to orienting attention (Corbetta and Shulman, 2002), these results may reflect the increased attention abilities demonstrated by bilingual compared to monolingual children (Costa et al., 2009, 2008; Singh et al., 2015; Thomas-Sunesson et al., 2016). Alternatively, the increased connectivity in the multilingual group could reflect control mechanisms that are necessary to manage cross-linguistic interactions to prevent interference when first and second languages are simultaneously activated (Kroll et al., 2015).

The multilingual group had weaker connectivity from the IFG to areas of the ventral attention network (middle frontal gyrus), which responds to relevant external stimuli (Corbetta \& Shulman, 2002; Fan et al., 2005), and the default mode network (anterior cingulate gyrus and inferior parietal gyrus), which is active when an individual is not focused on any particular task (Mak et al., 2017). These results may reflect increased cognitve demands for interference supression or greater independence between cognitive control and intrinsic connectivity (Kousaie et al,2017). Our findings further support the mounting evidence that both domain-general and executive control networks seem to be reorganized as a result of the bilingual experience (Abutalebi et al., 2008, 2012; Garbin et al., 2010; Rodriguez-Fornells et al., 2005; van Heuven et al, 2008). The weaker connectivity detected between the IFG and the left inferior and middle temporal gyrus in 
children raised in a multilingual environment could reflect deficits in lexical access experienced by bilinguals (Marchman et al., 2010), as reduced structural connectivity to this region has been associated with naming difficulties in older adults (Papagno, 2011; Stamatakis et al., 2011).

Similar functional connectivity maps were observed for the left pars orbitalis (BA 47) and pars triangularis (BA 45), suggesting that they may belong to the same functional cluster. The left pars orbitalis (BA 47) has been shown to be engaged during retrieval of information stored in the lateral temporal cortex, and the left pars triangularis (BA 45) is involved in the selection of relevant information among competitors (Badre et al., 2005). The absence of significant connectivity differences from the pars opercularis may reflect functional subspecialisation as it relates to language processing. Indeed, whereas semantic control tasks elicit stronger activity in the pars orbitalis (BA 47), phonological control task activate dorsal regions of the frontal cortex including the pars opercularis (BA 44)(Noonan et al., 2013). Though the current literature is unclear regarding the functional subspecialisation of the right IFG, our results suggest that the right opercularis (BA 44) and triangularis (BA 45) may be more tightly coupled than the pars orbitalis (BA 47). Given the classical left-lateralized "core-language" network view, these results point to the need to better characterize the role of the left and right IFG and their functional specialization to gain a deeper understanding of the mechanisms guiding language processing in general, in particular as they relate to the multilingual experience across the lifespan.

Previous studies have reported thicker left IFG cortex (Klein et al., 2014) (Mårtensson et al., 2012) and thinner right IFG cortex (Klein et al., 2014) in bilingual 
compared to monolingual adults, as well as increased gray matter density and volume in other left hemisphere structures (Mechelli et al., 2004; Ressel et al., 2012) Furthermore, these differences are mediated by age of acquisition and proficiency levels (Klein et al., 2014; Mårtensson et al., 2012; Mechelli et al., 2004; Stein et al., 2012). In our study, the multilingual group had a thicker left pars opercularis than the monolingual group, but no structural differences were significant after multiple comparison correction. While the uncorrected result is in line with previous findings, the fact that it was not significant after correction (despite similar power to previous studies) suggests that structural alterations to the IFG related to bilingualism may emerge later than functional differences. Childhood is a period of intense growth and neuroplasticity including substantial changes to cortical structure (Brown \& Jernigan, 2012; Remer et al., 2017). Cortical thinning occurs throughout childhood, but is most rapid during adolescence (Tamnes et al., 2017; Zhou et al., 2015), and thus brain changes related to bilingualism or multilingualism may become more apparent during this time.

The children in multilingual group were exposed to two or more languages between $10-50 \%$ of the time. While some of these children are unlikely to represent true simultaneous bilinguals, there were no significant relationships between functional connectivity in the significant clusters and the percent of time exposed to additional languages, suggesting that the specific amount of exposure did not play a large role in the IFG functional connectivity differences detected here.

A limitation of this study is that we did not acquire proficiency measures in the additional language(s). Both brain structure and function are related to language proficiency (Linkersdörfer et al., 2015; Mårtensson et al., 2012; Stein et al., 2012; 
reviewed in Grundy et al., 2017), so it is possible that group differences (or the lack thereof for brain structure) may reflect the fact that the children in this study were young and have not necessarily acquired proficiency in their other language(s). Measures of English language skills did not differ significantly between groups. However, there were significant group-by-language score interactions, where the monolingual group had positive relationships between language scores and functional connectivity from the IFG to the middle frontal gyrus, but the multilingual group had negative relationships. This is part of the ventral attention network, and an area where the multilingual group had weaker connectivity than the monolingual group. Thus, these interactions may reflect the increased attentional capabilities demonstrated by bilinguals over monolinguals particularly in ignoring conflicting or misleading cues (Bialystok \& Martin, 2004; Costa et al., 2008), and the way in which this affects developing language skills. Future studies that are able to assess proficiency in both (or all) languages would provide greater insight into how children's brains develop as they learn multiple languages. Another limitation of this study is the relatively small sample size, though the monolingual and multilingual environment groups were well matched on age and sex. Future studies with larger sample sizes and more power may be able to further tease apart the influence of other factors such as the number of languages being exposed to and proficiency on developing brain function and structure.

\section{Conclusion}

In conclusion, these results show that young children growing up in a multilingual environment have a more integrated functional language network that is less functionally 
connected to parts of the default mode and ventral attention networks than children growing up in a monolingual environment. These results support the notion that functional brain differences observed in the IFG of bilingual adults may result from developmental changes associated with second language learning during a critical period of early brain and language development. The lack of group differences in cortical structure of the IFG suggest that structural changes related to bilingualism/multilingualism occur later in childhood or adolescence. Our study demonstrates that functional changes related to multilingualism are already apparent in young children, and provides new insight into the mechanisms that underlie the cognitive advantages associated with learning more than one language.

\section{Acknowledgements}

This work was supported by the Canadian Institutes of Health Research (CIHR), funding reference numbers IHD-134090 and MOP-136797, and a grant from the Alberta Children's Hospital Research Institute. Salary support provided by the University of Calgary's NSERC CREATE I3T program (XL) and CIHR (CL). 


\section{References}

Abutalebi, J. (2008). Neural aspects of second language representation and language control. Acta Psychologica, 128(3), 466-478. https://doi.org/10.1016/j.actpsy.2008.03.014

Abutalebi, J., Della Rosa, P. A., Green, D. W., Hernandez, M., Scifo, P., Keim, R., ... Costa, A. (2012). Bilingualism Tunes the Anterior Cingulate Cortex for Conflict Monitoring. Cerebral Cortex, 22(9), 2076-2086. https://doi.org/10.1093/cercor/bhr287

Adesope, O. O., Lavin, T., Thompson, T., \& Ungerleider, C. (2010). A Systematic Review and Meta-Analysis of the Cognitive Correlates of Bilingualism. Review of Educational Research, 80(2), 207-245. https://doi.org/10.3102/0034654310368803

Badre, D., Poldrack, R. A., Paré-Blagoev, E. J., Insler, R. Z., Wagner, A. D., Ding, G., ... Weng, X. (2005). Dissociable controlled retrieval and generalized selection mechanisms in ventrolateral prefrontal cortex. Neuron, 47(6), 907-918. https://doi.org/10.1016/j.neuron.2005.07.023

Barac, R., Bialystok, E., Castro, D. C., \& Sanchez, M. (2014). The cognitive development of young dual language learners: A critical review. Early Childhood Research Quarterly, 29(4), 699-714. https://doi.org/10.1016/j.ecresq.2014.02.003

Berken, J. A., Chai, X., Chen, J.-K. J.-K., Gracco, V. L., \& Klein, D. (2016). Effects of Early and Late Bilingualism on Resting-State Functional Connectivity. Journal of Neuroscience, 36(4), 1165-1172. https://doi.org/10.1523/JNEUROSCI.196015.2016

Berken, J. A., Gracco, V. L., \& Klein, D. (2017). Early bilingualism, language attainment, and brain development. Neuropsychologia, 98, 220-227. https://doi.org/10.1016/j.neuropsychologia.2016.08.031

Bialystok, E., Craik, F. I. M., Grady, C., Chau, W., Ishii, R., Gunji, A., \& Pantev, C. (2005). Effect of bilingualism on cognitive control in the Simon task: evidence from MEG. NeuroImage, 24(1), 40-49. https://doi.org/10.1016/j.neuroimage.2004.09.044

Bialystok, E., Craik, F. I. M., Klein, R., \& Viswanathan, M. (2004). Bilingualism, Aging, and Cognitive Control: Evidence From the Simon Task. Psychology and Aging, 19(2), 290-303. https://doi.org/10.1037/0882-7974.19.2.290

Bialystok, E., \& Martin, M. M. (2004). Attention and inhibition in bilingual children: evidence from the dimensional change card sort task. Developmental Science, 7(3), 325-339. https://doi.org/10.1111/j.1467-7687.2004.00351.x

Bialystok, E., \& Senman, L. (2004). Executive Processes in Appearance-Reality Tasks: The Role of Inhibition of Attention and Symbolic Representation. Child Development, 75(2), 562-579. https://doi.org/10.1111/j.1467-8624.2004.00693.x

Bialystok, E., \& Shapero, D. (2005). Ambiguous benefits: the effect of bilingualism on reversing ambiguous figures. Developmental Science, 8(6), 595-604. https://doi.org/10.1111/j.1467-7687.2005.00451.x

Brown, T. T., \& Jernigan, T. L. (2012). Brain development during the preschool years. Neuropsychology Review, 22(4), 313-333. https://doi.org/10.1007/s11065-0129214-1

Chai, X. J., Berken, J. A., Barbeau, E. B., Soles, J., Callahan, M., Chen, J.-K., \& Klein, 
D. (2016). Intrinsic Functional Connectivity in the Adult Brain and Success in Second-Language Learning. Journal of Neuroscience, 36(3), 755-761.

https://doi.org/10.1523/JNEUROSCI.2234-15.2016

Coderre, E. L., Smith, J. F., Van Heuven, W. J. B., \& Horwitz, B. (2016). The functional overlap of executive control and language processing in bilinguals. Bilingualism: Language and Cognition, 19(03), 471-488. https://doi.org/10.1017/S1366728915000188

Corbetta, M., \& Shulman, G. L. (2002). Control of goal-directed and stimulus-driven attention in the brain. Nature Reviews Neuroscience, 3(3), 201-215. https://doi.org/10.1038/nrn755

Costa, A., Hernández, M., Costa-Faidella, J., \& Sebastián-Gallés, N. (2009). On the bilingual advantage in conflict processing: Now you see it, now you don't. Cognition, 113(2), 135-149. https://doi.org/10.1016/j.cognition.2009.08.001

Costa, A., Hernández, M., \& Sebastián-Gallés, N. (2008). Bilingualism aids conflict resolution: Evidence from the ANT task. Cognition, 106(1), 59-86. https://doi.org/10.1016/j.cognition.2006.12.013

Cox, R. W. (1996). AFNI: Software for Analysis and Visualization of Functional Magnetic Resonance Neuroimages. Computers and Biomedical Research, 29(3), 162-173. https://doi.org/10.1006/cbmr.1996.0014

Desikan, R. S., Ségonne, F., Fischl, B., Quinn, B. T., Dickerson, B. C., Blacker, D., ... Killiany, R. J. (2006). An automated labeling system for subdividing the human cerebral cortex on MRI scans into gyral based regions of interest. NeuroImage, 31(3), 968-980. https://doi.org/10.1016/j.neuroimage.2006.01.021

European Commission, Directorate-General for Education and Culture, D.-G. for T. and D.-G. for I. and co-ordinated by D.-G. for C. (2012). EUROPEANS AND THEIR LANGUAGES REPORT Europeans and their Languages. Special Eurobarometer 386. Retrieved from http://ec.europa.eu/public_opinion/index_en.htm

Fan, J., McCandliss, B. D., Fossella, J., Flombaum, J. I., \& Posner, M. I. (2005). The activation of attentional networks. NeuroImage, 26(2), 471-479. https://doi.org/10.1016/J.NEUROIMAGE.2005.02.004

Fischl, B. (2012). FreeSurfer. NeuroImage, 62(2), 774-781. https://doi.org/10.1016/j.neuroimage.2012.01.021

Fonov, V., Evans, A. C., Botteron, K., Almli, C. R., McKinstry, R. C., \& Collins, D. L. (2011). Unbiased average age-appropriate atlases for pediatric studies. NeuroImage, 54(1), 313-327. https://doi.org/10.1016/j.neuroimage.2010.07.033

Fonov, V., Evans, A., McKinstry, R., \& Almli, C. (2009). Unbiased nonlinear average age-appropriate brain templates from birth to adulthood. NeuroImage. Retrieved from https:/www.infona.pl/resource/bwmeta1.element.elsevier-22edcca2-af853025-a371-3f49c018e71f

Garbin, G., Sanjuan, A., Forn, C., Bustamante, J. C., Rodriguez-Pujadas, A., Belloch, V., ... Ávila, C. (2010). Bridging language and attention: Brain basis of the impact of bilingualism on cognitive control. NeuroImage, 53(4), 1272-1278. https://doi.org/10.1016/j.neuroimage.2010.05.078

Genovese, C. R., Lazar, N. A., \& Nichols, T. (2002). Thresholding of Statistical Maps in Functional Neuroimaging Using the False Discovery Rate. NeuroImage, 15(4), 870878. https://doi.org/10.1006/nimg.2001.1037 
Gollan, T. H., Montoya, R. I., \& Werner, G. A. (2002). Semantic and letter fluency in Spanish-English bilinguals. Neuropsychology, 16(4), 562-576. Retrieved from http://www.ncbi.nlm.nih.gov/pubmed/12382994

Grundy, J. G., Anderson, J. A. E., \& Bialystok, E. (2017). Neural correlates of cognitive processing in monolinguals and bilinguals. Annals of the New York Academy of Sciences, 1396(1), 183-201. https://doi.org/10.1111/nyas.13333

Hakuta, K., Bialystok, E., \& Wiley, E. (2003). Critical Evidence. Psychological Science, 14(1), 31-38. https://doi.org/10.1111/1467-9280.01415

Hernandez, A. E., Woods, E. A., \& Bradley, K. A. L. L. (2015). Neural correlates of single word reading in bilingual children and adults. Brain and Language, 143, 1119. https://doi.org/10.1016/j.bandl.2015.01.010

Jenkinson, M., Beckmann, C. F., Behrens, T. E. J., Woolrich, M. W., \& Smith, S. M. (2012). FSL. NeuroImage, 62(2), 782-790. https://doi.org/10.1016/j.neuroimage.2011.09.015

Johnson, J. S. (1992). Critical Period Effects in Second Language Acquisition: The Effect of Written versus Auditory Materials on the Assessment of Grammatical Competence. Language Learning, 42(2), 217-248. https://doi.org/10.1111/J.14671770.1992.TB00708.X

Johnson, J. S., \& Newport, E. L. (1989). Critical period effects in second language learning: The influence of maturational state on the acquisition of English as a second language. Cognitive Psychology, 21(1), 60-99. https://doi.org/10.1016/00100285(89)90003-0

Jones, O. P., Green, D. W., Grogan, A., Pliatsikas, C., Filippopolitis, K., Ali, N., ... Price, C. J. (2012). Where, when and why brain activation differs for bilinguals and monolinguals during picture naming and reading aloud. Cerebral Cortex, 22(4), 892-902. https://doi.org/10.1093/cercor/bhr161

Kaplan, B. J., Giesbrecht, G. F., Leung, B. M. Y., Field, C. J., Dewey, D., Bell, R. C., ... APrON Study Team. (2014). The Alberta Pregnancy Outcomes and Nutrition (APrON) cohort study: rationale and methods. Maternal \& Child Nutrition, 10(1), 44-60. https://doi.org/10.1111/j.1740-8709.2012.00433.x

Klein, D., Milner, B., Zatorre, R. J., Meyer, E., \& Evans, A. C. (1995). The neural substrates underlying word generation: a bilingual functional-imaging study. Proceedings of the National Academy of Sciences of the United States of America, 92(7), 2899-2903. Retrieved from http://www.ncbi.nlm.nih.gov/pubmed/7708745

Klein, D., Mok, K., Chen, J.-K., \& Watkins, K. E. (2014). Age of language learning shapes brain structure: a cortical thickness study of bilingual and monolingual individuals. Brain and Language, 131, 20-24. https://doi.org/10.1016/j.bandl.2013.05.014

Korkman, M., Kirk, U., \& Kemp, S. (2007). NEPSY-II: Clinical and interpretive manual. San Antonio, TX: The Psychological Corporation.

Kousaie, S., J.Chai, X., Kaija, M. S., \& Klein, D. (2017). Simultaneous learning of two languages from birth positively impacts intrinsic functional connectivity and cognitive control. Brain and Cognition, 117, 49-56. https://doi.org/10.1016/J.BANDC.2017.06.003

Kovács, A. M., \& Mehler, J. (2009a). Cognitive gains in 7-month-old bilingual infants. Proceedings of the National Academy of Sciences of the United States of America, 
106(16), 6556-6560. https://doi.org/10.1073/pnas.0811323106

Kovács, A. M., \& Mehler, J. (2009b). Flexible Learning of Multiple Speech Structures in Bilingual Infants. Science, 325(5940), 611-612. https://doi.org/10.1126/science. 1173947

Kovelman, I., Baker, S. A., \& Petitto, L.-A. (2008). Bilingual and monolingual brains compared: a functional magnetic resonance imaging investigation of syntactic processing and a possible \&quot;neural signature\&quot; of bilingualism. Journal of Cognitive Neuroscience, 20(1), 153-169. https://doi.org/10.1162/jocn.2008.20011

Kovelman, I., Shalinsky, M. H., Berens, M. S., \& Petitto, L.-A. (2008). Shining new light on the brain's \&quot;bilingual signature\&quot;: a functional Near Infrared Spectroscopy investigation of semantic processing. NeuroImage, 39(3), 1457-1471. https://doi.org/10.1016/j.neuroimage.2007.10.017

Koyama, M. S., Di Martino, A., Zuo, X.-N., Kelly, C., Mennes, M., Jutagir, D. R., ... Milham, M. P. (2011). Resting-State Functional Connectivity Indexes Reading Competence in Children and Adults. Journal of Neuroscience, 31(23), 8617-8624. https://doi.org/10.1523/JNEUROSCI.4865-10.2011

Kroll, J. F., Gullifer, J. W., McClain, R., Rossi, E., \& Martín, M. C. (2015). Selection and control in bilingual comprehension and production. In J. W. Schwieter (Ed.), The Cambridge Handbook of Bilingual Processing (pp. 485-507). Cambridge: Cambridge University Press. https://doi.org/DOI: 10.1017/CBO9781107447257.021

Lepage, J.-F., \& Corbeil, J.-P. (2013). The evolution of English-French bilingualism in Canada from 1961 to 2011 Insights on Canadian Society. Retrieved from http://www.statcan.gc.ca/pub/75-006-x/2013001/article/11795-eng.pdf

Linkersdörfer, J., Jurcoane, A., Lindberg, S., Kaiser, J., Hasselhorn, M., Fiebach, C. J., \& Lonnemann, J. (2015). The Association between Gray Matter Volume and Reading Proficiency: A Longitudinal Study of Beginning Readers. Journal of Cognitive Neuroscience, 27(2), 308-318. https://doi.org/10.1162/jocn_a_00710

Logan, J. A. R., Schatschneider, C., \& Wagner, R. K. (2011). Rapid serial naming and reading ability: The role of lexical access. Reading and Writing, 24(1), 1-25.

Mak, L. E., Minuzzi, L., MacQueen, G., Hall, G., Kennedy, S. H., \& Milev, R. (2017). The Default Mode Network in Healthy Individuals: A Systematic Review and MetaAnalysis. Brain Connectivity, 7(1), 25-33. https://doi.org/10.1089/brain.2016.0438

Marchman, V. A., Fernald, A., \& Hurtado, N. (2010). How vocabulary size in two languages relates to efficiency in spoken word recognition by young SpanishEnglish bilinguals. Journal of Child Language, 37(4), 817-840. https://doi.org/10.1017/S0305000909990055

Mårtensson, J., Eriksson, J., Bodammer, N. C., Lindgren, M., Johansson, M., Nyberg, L., \& Lövdén, M. (2012). Growth of language-related brain areas after foreign language learning. NeuroImage, 63(1), 240-244. https://doi.org/10.1016/j.neuroimage.2012.06.043

Martin, A., Schurz, M., Kronbichler, M., \& Richlan, F. (2015). Reading in the brain of children and adults: A meta-analysis of 40 functional magnetic resonance imaging studies. Human Brain Mapping, 36(5), 1963-1981. https://doi.org/10.1002/hbm.22749

Mechelli, A., Crinion, J. T., Noppeney, U., O’Doherty, J., Ashburner, J., Frackowiak, R. S., \& Price, C. J. (2004). Neurolinguistics: Structural plasticity in the bilingual brain. 
Nature, 431(7010), 757-757. https://doi.org/10.1038/431757a

Mei, L., Xue, G., Lu, Z.-L., Chen, C., Zhang, M., He, Q., ... Dong, Q. (2014). Learning to read words in a new language shapes the neural organization of the prior languages. Neuropsychologia, 65, 156-168.

https://doi.org/10.1016/j.neuropsychologia.2014.10.019

Noonan, K. A., Jefferies, E., Visser, M., \& Lambon Ralph, M. A. (2013). Going beyond Inferior Prefrontal Involvement in Semantic Control: Evidence for the Additional Contribution of Dorsal Angular Gyrus and Posterior Middle Temporal Cortex. Journal of Cognitive Neuroscience, 25(11), 1824-1850. https://doi.org/10.1162/jocn_a_00442

O’Neill, D. K. (2007). The Language Use Inventory for Young Children: A ParentReport Measure of Pragmatic Language Development for 18- to 47-Month-Old Children. Journal of Speech Language and Hearing Research, 50(1), 214. https://doi.org/10.1044/1092-4388(2007/017)

Oyama, S. (1976). A sensitive period for the acquisition of a nonnative phonological system. Journal of Psycholinguistic Research, 5(3), 261-283. https://doi.org/10.1007/BF01067377

Papagno, C. (2011). Naming and the Role of the Uncinate Fasciculus in Language Function. Current Neurology and Neuroscience Reports, 11(6), 553-559. https://doi.org/10.1007/s11910-011-0219-6

Patkowski, M. S. (1980). The sensitive period for the acquisition of syntax in a second language. Language Learning, 30(2), 449-468. https://doi.org/10.1111/j.14671770.1980.tb00328.x

Pugh, K. R., Shaywitz, B. A., Shaywitz, S. E., Constable, R. T., Skudlarski, P., Fulbright, R. K., ... Gore, J. C. (1996). Cerebral organization of component processes in reading. Brain : A Journal of Neurology, 119 ( Pt 4), 1221-1238. Retrieved from http://www.ncbi.nlm.nih.gov/pubmed/8813285

Remer, J., Croteau-Chonka, E., Dean Iii, D. C., D 'arpino, S., Dirks, H., Whiley, D., \& Deoni, S. C. L. (2017). Quantifying cortical development in typically developing toddlers and young children, 1-6 years of age. https://doi.org/10.1016/j.neuroimage.2017.04.010

Ressel, V., Pallier, C., Ventura-Campos, N., Díaz, B., Roessler, A., Ávila, C., \& Sebastián-Gallés, N. (2012). An effect of bilingualism on the auditory cortex. The Journal of Neuroscience: The Official Journal of the Society for Neuroscience, 32(47), 16597-16601. https://doi.org/10.1523/JNEUROSCI.1996-12.2012

Rodriguez-Fornells, A., Lugt, A. van der, Rotte, M., Britti, B., Heinze, H.-J., \& Münte, T. F. (2005). Second Language Interferes with Word Production in Fluent Bilinguals: Brain Potential and Functional Imaging Evidence. Journal of Cognitive Neuroscience, 17(3), 422-433. https://doi.org/10.1162/0898929053279559

Ryan, C. (2013). Language Use in the United States: 2011. Retrieved from https://www.census.gov/prod/2013pubs/acs-22.pdf

Sadat, J., Martin, C. D., Alario, F. X., \& Costa, A. (2012). Characterizing the Bilingual Disadvantage in Noun Phrase Production. Journal of Psycholinguistic Research, 41(3), 159-179. https://doi.org/10.1007/s10936-011-9183-1

Singh, L., Fu, C. S. L., Rahman, A. A., Hameed, W. B., Sanmugam, S., Agarwal, P., ... GUSTO Research Team. (2015). Back to basics: a bilingual advantage in infant 
visual habituation. Child Development, 86(1), 294-302.

https://doi.org/10.1111/cdev.12271

Stamatakis, E. A., Shafto, M. A., Williams, G., Tam, P., \& Tyler, L. K. (2011). White matter changes and word finding failures with increasing age. PloS One, 6(1), e14496. https://doi.org/10.1371/journal.pone.0014496

Stein, M., Federspiel, A., Koenig, T., Wirth, M., Strik, W., Wiest, R., ... Dierks, T. (2012). Structural plasticity in the language system related to increased second language proficiency. Cortex, 48(4), 458-465. https://doi.org/10.1016/j.cortex.2010.10.007

Stevens, G. (1999). Age at Immigration and Second Language Proficiency among Foreign-Born Adults. Language in Society. Cambridge University Press. https://doi.org/10.2307/4168963

Tamnes, C. K., Herting, M. M., Goddings, A.-L., Meuwese, R., Blakemore, S.-J., Dahl, R. E., ... Mills, K. L. (2017). Development of the Cerebral Cortex across Adolescence: A Multisample Study of Inter-Related Longitudinal Changes in Cortical Volume, Surface Area, and Thickness. The Journal of Neuroscience, 37(12), 3402-3412. https://doi.org/10.1523/JNEUROSCI.3302-16.2017

Thomas-Sunesson, D., Hakuta, K., \& Bialystok, E. (2016). Degree of bilingualism modifies executive control in Hispanic children in the USA. International Journal of Bilingual Education and Bilingualism, 1-10. https://doi.org/10.1080/13670050.2016.1148114

Tzourio-Mazoyer, N., Landeau, B., Papathanassiou, D., Crivello, F., Etard, O., Delcroix, N., ... Joliot, M. Automated Anatomical Labeling of Activations in SPM Using a Macroscopic Anatomical Parcellation of the MNI MRI Single-Subject Brain, 15 NeuroImage $\S$ (2002). https://doi.org/10.1006/nimg.2001.0978

van Heuven, W. J. B., Schriefers, H., Dijkstra, T., \& Hagoort, P. (2008). Language Conflict in the Bilingual Brain. Cerebral Cortex, 18(11), 2706-2716. https://doi.org/10.1093/cercor/bhn030

Wartenburger, I., Heekeren, H. R., Abutalebi, J., Cappa, S. F., Villringer, A., \& Perani, D. (2003). Early setting of grammatical processing in the bilingual brain. Neuron, 37(1), 159-170. Retrieved from http://www.ncbi.nlm.nih.gov/pubmed/12526781

Yamamoto, K., \& Sakai, K. L. (2016). The Dorsal Rather than Ventral Pathway Better Reflects Individual Syntactic Abilities in Second Language. Frontiers in Human Neuroscience, 10, 295. https://doi.org/10.3389/fnhum.2016.00295

Zhang, M., Li, J., Chen, C., Xue, G., Lu, Z., Mei, L., ... Dong, Q. (2014). Resting-state functional connectivity and reading abilities in first and second languages. NeuroImage, 84, 546-553. https://doi.org/10.1016/j.neuroimage.2013.09.006

Zhou, D., Lebel, C., Treit, S., Evans, A., \& Beaulieu, C. (2015). Accelerated longitudinal cortical thinning in adolescence. NeuroImage, 104, 138-145. https://doi.org/10.1016/j.neuroimage.2014.10.005 


\section{Figures and tables}

Table 1: Demographic information. Scaled scores are standardized for age.

\begin{tabular}{|c|c|c|c|c|c|}
\hline & \multicolumn{2}{|c|}{ Monolingual $(\mathrm{n}=22)$} & \multicolumn{2}{|c|}{ Multilingual $(\mathrm{n}=22)$} & \multirow[t]{2}{*}{ p-value } \\
\hline & Range & Mean \pm SD & Range & Mean & \\
\hline Age (years) & $3.8-5.9$ & $4.8 \pm 0.6$ & $3.5-6.3$ & $4.8 \pm 0.7$ & 0.90 \\
\hline Sex (male/female) & $13 / 9$ & & $13 / 9$ & & 1.00 \\
\hline $\begin{array}{l}\text { Age (years) at first } \\
\text { exposure to language(s) } \\
\text { other than English }\end{array}$ & $\mathrm{n} / \mathrm{a}$ & $\mathrm{n} / \mathrm{a}$ & $0-3$ & $0.6 \pm 1.2$ & $\mathrm{n} / \mathrm{a}$ \\
\hline $\begin{array}{l}\text { Percentage }(\%) \text { of time } \\
\text { exposed to other } \\
\text { language(s) }\end{array}$ & $\mathrm{n} / \mathrm{a}$ & $\mathrm{n} / \mathrm{a}$ & $10-50$ & $23.6 \pm 14.2$ & $\mathrm{n} / \mathrm{a}$ \\
\hline $\begin{array}{l}\text { Maternal education (y } \\
\text { post-secondary) }\end{array}$ & $1-12$ & $6 \pm 3$ & $1.5-11$ & $5 \pm 3$ & 0.58 \\
\hline Household Income & $\begin{array}{c}\$ 50,000 \text { - over } \\
\$ 175,000\end{array}$ & $\begin{array}{l}\$ 100,000- \\
\$ 124,999\end{array}$ & $\begin{array}{l}\$ 25,000 \text { - over } \\
\$ 175,000\end{array}$ & $\begin{array}{l}\$ 100,000- \\
\$ 124,999\end{array}$ & 0.77 \\
\hline $\begin{array}{l}\text { Phonological Processing } \\
\text { (Scaled score) }\end{array}$ & $7-15$ & $10.7 \pm 2.4$ & $6-16$ & $11.3 \pm 2.3$ & 0.46 \\
\hline $\begin{array}{l}\text { Speeded Naming } \\
\text { (Scaled score) }\end{array}$ & $7-16$ & $11.2 \pm 2.7$ & $7-18$ & $12.6 \pm 2.5$ & 0.11 \\
\hline
\end{tabular}


Table 2: Cortical regions with significant differences in functional connectivity from

the inferior frontal gyrus (multilingual versus monolingual groups).

\begin{tabular}{|c|c|c|c|c|c|c|c|c|}
\hline \multirow[b]{2}{*}{ Anatomical regions } & \multirow{2}{*}{$\begin{array}{l}\text { Brodmann } \\
\text { Area (BA) }\end{array}$} & \multicolumn{3}{|c|}{ MNI coordinate } & \multirow{2}{*}{$\begin{array}{l}\text { Peak value } \\
\text { ( } \mathrm{Z} \text { value) }\end{array}$} & \multirow{2}{*}{$\begin{array}{c}\text { Cluster } \\
\text { size } \\
(\mathrm{mm} 3)\end{array}$} & \multicolumn{2}{|c|}{ Effect size } \\
\hline & & $\mathrm{x}$ & $\mathrm{y}$ & $\mathrm{z}$ & & & $\begin{array}{c}\text { Cohen's } \\
\text { d }\end{array}$ & $\begin{array}{l}\text { Effect- } \\
\text { size } r\end{array}$ \\
\hline \multicolumn{9}{|c|}{ Left pars triangularis (BA 45) } \\
\hline $\begin{array}{c}\text { Bilateral superior } \\
\text { parietal lobule }\end{array}$ & BA7 & 8 & -56 & 57 & 4.26 & 4401 & 1.14 & 0.49 \\
\hline $\begin{array}{l}\text { Left Inferior and } \\
\text { Middle temporal } \\
\text { gyrus }\end{array}$ & $\begin{array}{l}\mathrm{BA} 20 / \\
\mathrm{BA} 21\end{array}$ & -49 & -14 & -42 & -4.29 & 3564 & -1.37 & -0.56 \\
\hline \multicolumn{9}{|c|}{ Left pars orbitalis (BA 47) } \\
\hline $\begin{array}{c}\text { Bilateral Superior } \\
\text { parietal lobule }\end{array}$ & BA7 & 26 & -50 & 51 & 5.1111 & 13014 & 1.32 & 0.55 \\
\hline $\begin{array}{c}\text { Left Middle frontal } \\
\text { gyrus }\end{array}$ & BA10 & -34 & 61 & -3 & -3.5589 & 2619 & -0.94 & -0.42 \\
\hline \multicolumn{9}{|c|}{ Right pars triangularis (BA 45) } \\
\hline $\begin{array}{c}\text { Anterior cingulate } \\
\text { gyrus }\end{array}$ & BA24 & -4 & 28 & 18 & -3.97 & 3294 & -1.10 & -0.48 \\
\hline \multicolumn{9}{|c|}{ Right pars opercularis (BA 44) } \\
\hline $\begin{array}{l}\text { Anterior cingulate } \\
\text { gyrus }\end{array}$ & BA32 & -10 & 31 & 24 & -5.5628 & 7722 & -1.29 & -0.54 \\
\hline $\begin{array}{l}\text { Left Inferior parietal } \\
\text { lobule }\end{array}$ & BA40 & -46 & -26 & 21 & -3.1501 & 3483 & -1.11 & -0.48 \\
\hline \multicolumn{9}{|c|}{ Right pars orbitalis (BA 47) } \\
\hline $\begin{array}{l}\text { Left Middle frontal } \\
\text { gyrus }\end{array}$ & BA9 & -16 & 46 & 33 & -4.2418 & 3051 & -1.37 & -0.56 \\
\hline
\end{tabular}


a)

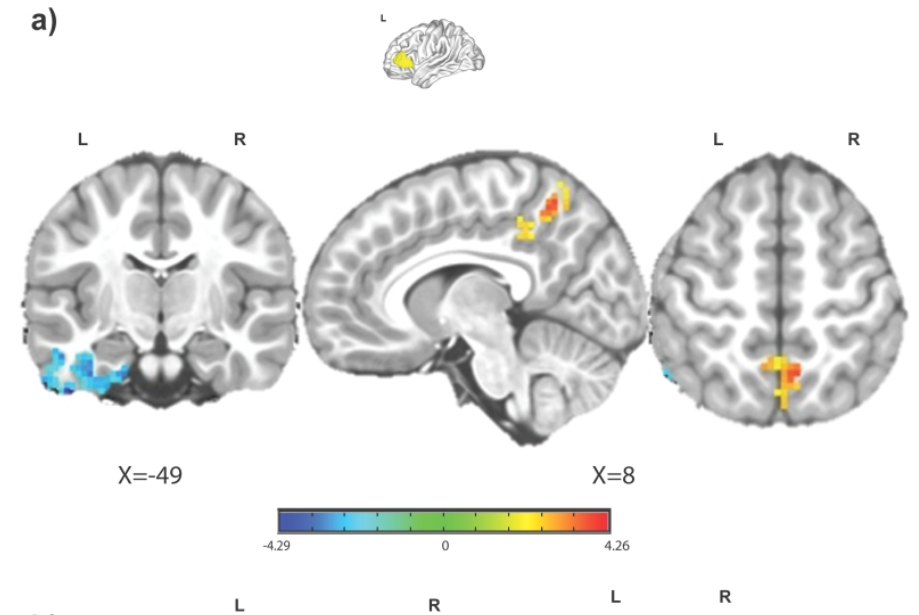

b)

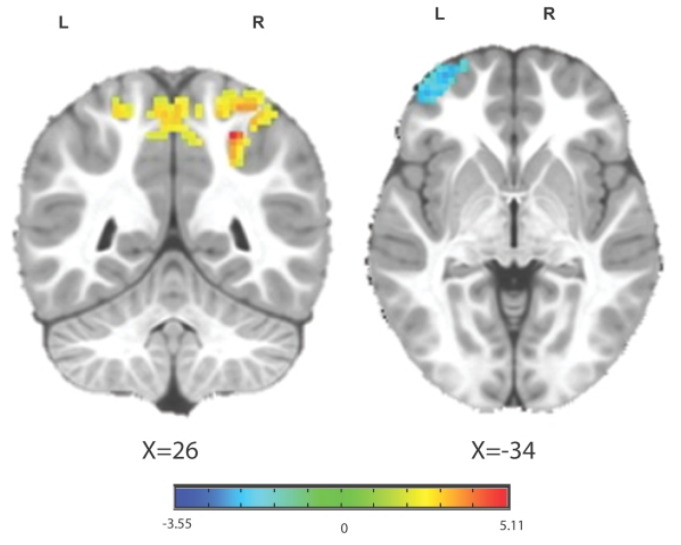

Figure 1: Group difference in functional connectivity from the left IFG. Regions of interest were extracted from the AAL template and are shown on anatomical volume in standard space; pars opercularis in blue, pars triangularis in green and pars orbitalis in red. Significant group differences in resting-state functional connectivity from the left pars triangularis (a) and left pars orbitalis (b) were detected. Children in the multilingual group had increased connectivity (red/yellow) to the bilateral superior parietal regions. Decreased connectivity in the multilingual group (blue) was observed between the left pars triangularis (seed) and left temporal areas, as well as between the pars orbitalis (seed) and the left middle frontal gyrus. There were no significant group differences in functional connectivity from the left pars opercularis; t-statistical parametric maps are 
shown on an anatomical volume in standard space. Clusters survived a height threshold of uncorrected $\mathrm{p}<0.01$ and an extent threshold of FWE-corrected $\mathrm{p}<0.05$ at the cluster level. 


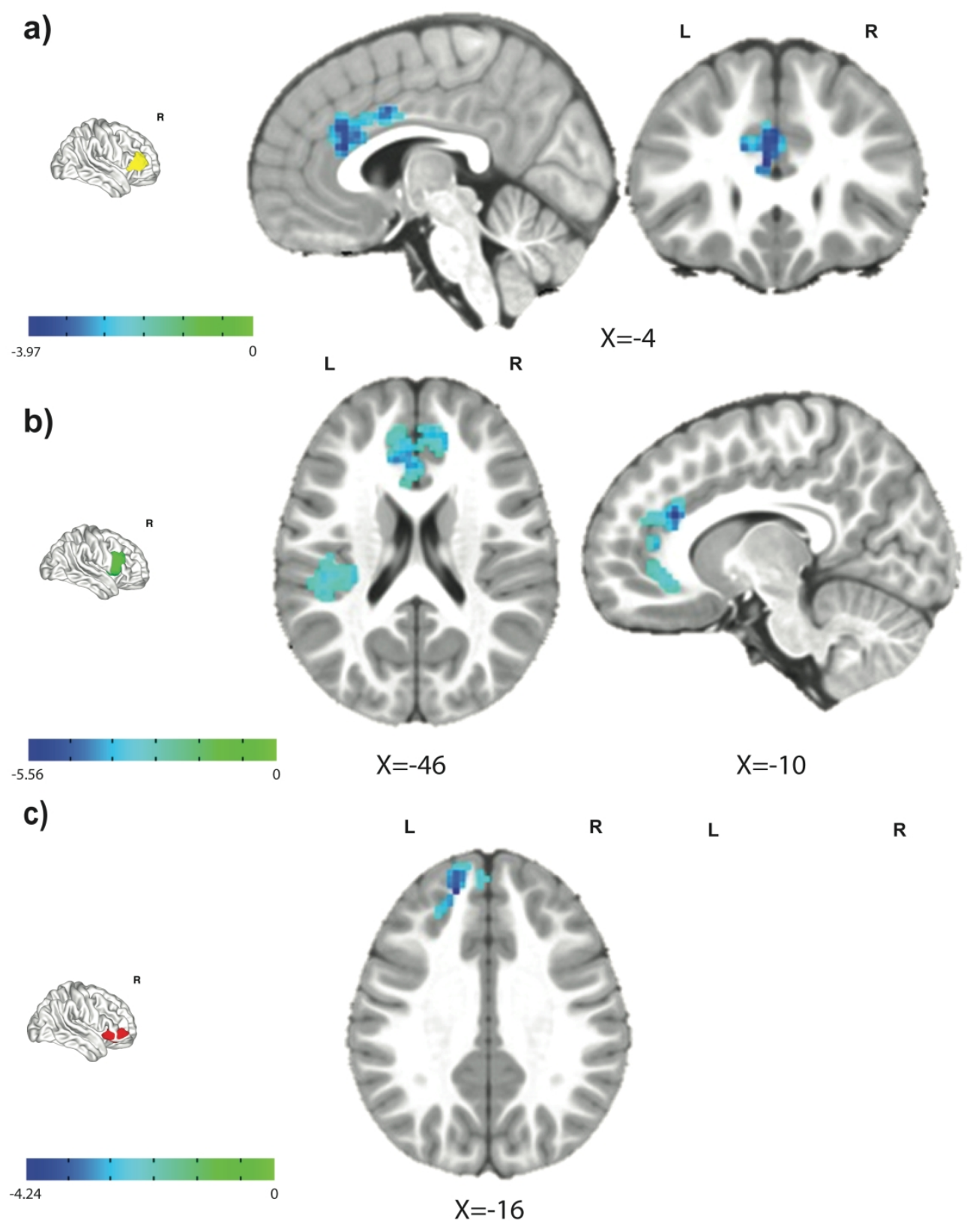

Figure 2: Group differences in functional connectivity from the right IFG. Regions

of interest were extracted from the AAL template and are shown on anatomical volume in standard space; pars triangularis in yellow, pars orbitalis in red and pars opercularis in green. Significant group differences in resting state functional connectivity from the right pars triangularis (a), pars opercularis (b) and pars orbitalis (c). Children in the 
multilingual group displayed decreased connectivity (blue) from the right pars triangularis (b), pars opercularis (b) and pars opercularis (b) to the cingulate cortex. They also displayed decreased connectivity from the pars orbitalis to the left middle frontal gyrus and the pars opercularis to the Left Inferior parietal lobule; as well as increased connectivity from right pars orbitalis (red/yellow) to bilateral superior parietal regions; tstatistical parametric maps are shown on an anatomical volume in standard space. Clusters survived a height threshold of uncorrected $\mathrm{p}<0.01$ and an extent threshold of FWE-corrected $\mathrm{p}<0.05$ at the cluster level. 


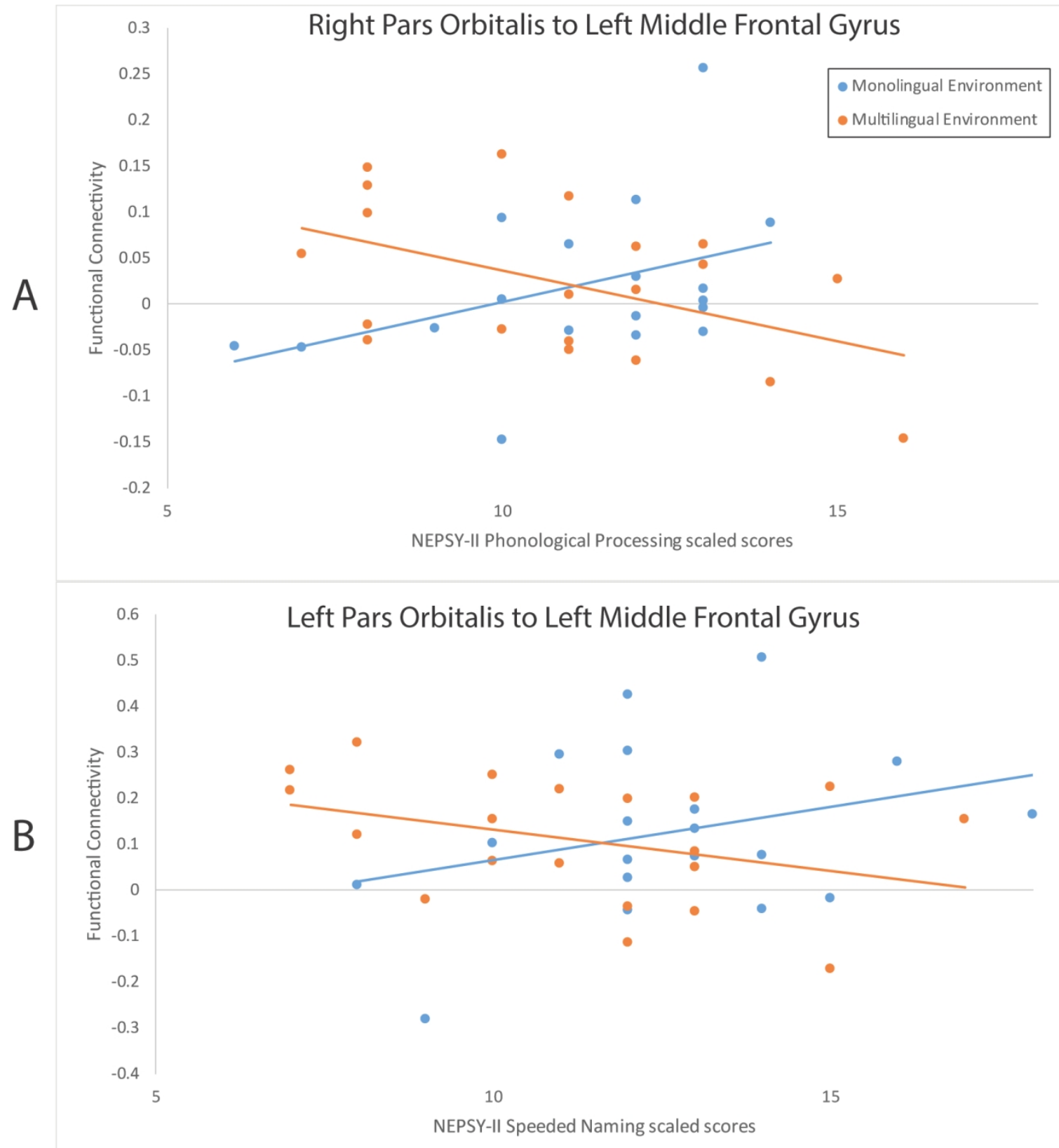

Figure 3: Significant interactions between group and language scores. (A) For children in a monolingual environment, NEPSY-II Phonological Processing Scaled Scores were positively associated with functional connectivity between the right pars orbitalis and the left middle frontal gyrus; for children in a multilingual environment, the relationship was negative. (B) A similar interaction was found for Speeded Naming 
scores and functional connectivity between the left pars orbitalis and the left middle frontal gyrus. 